\title{
Endometrial Scratching in Women with Recurrent First Trimester Pregnancy Loss: A Randomized Controlled Trial
}

\author{
Abdelhamid Shaheen \\ Department of Obstetrics and Gynecology, Faculty of Medicine, Menoufia University, Menoufia, \\ Egypt \\ Abdelhamidshaheen@yahoo.com
}

\begin{abstract}
:
Objective: to assess the role of endometrial scratching prior to ovulation induction to improve live birth rate in recurrent first trimester pregnancy loss.

Methods: This randomized controlled trial included 126 patients with recurrent first trimester spontaneous miscarriage with no obvious cause who were assigned into two groups; the study group $(n=62)$ who underwent endometrial scratching once with a pipelle de Cornier and the control group $(n=64)$ who underwent placebo procedure, followed by ovulation induction. Live birth rate was the primary outcome in this study. Data was collected and tabulated.

Results: There was a significant difference between the two groups regarding the miscarriage rate which was higher in the control group $(p<0.05)$ and live pregnancy rate which was higher in the study group $(p<0.05)$. There was no significant difference between the two groups regarding clinical pregnancy rate, multiple pregnancy rate, preterm delivery, admission to NICU and neonatal death ( $p>0.05)$.

Conclusion: Endometrial scratching may improve live birth rates in couples with unexplained recurrent first trimester spontaneous miscarriage. Larger multicenter studies are warranted to confirm or refute these findings.
\end{abstract}

Keywords: Endometrial scratching, recurrent miscarriage.

\section{INTRODUCTION}

Endometrial scratching or injury is defined as intentional damage to the endometrium, such as biopsy or curettage, in women undergoing assisted reproduction technology (ART) to improve endometrial receptivity (1).

The first work suggesting that endometrial scratching doubles the chance of pregnancy in subsequent ART procedures was a prospective case-control non-randomized study performed on good responders who had failed to conceive in one or more previous IVF cycles transferring a mean number of more than three embryos in each arm (2).

More than a decade later, based on that evidence, several studies were conducted to prove its efficacy in women with repeated implantation failure and in ART cycles (3-6).

The aim of this study was to assess the role of endometrial scratching prior to ovulation induction to improve live birth rate in recurrent first trimester pregnancy loss.

\section{MATERIALS AND METHODS}

\subsection{Study Design}

This was a single center balanced randomized parallel group study carried out at the Department of Obstetrics and Gynecology, Menoufia University Hospital, Egypt , from September 2014 to August 2015.

The respective approvals of the review board and the ethics committee of the Menoufia Faculty of medicine were obtained.

The study protocol and its benefits and complications were explained to all participants, and all recruited patients completed and signed the 'informed consent' form. 


\subsection{Participants}

Patients with repeated first trimester spontaneous miscarriage (> 3 times) with no obvious cause after thorough investigations ( including Parental karyotyping, Antiphospholipid antibodies, Thrombophilia screen, Thyroid function tests, glucose tolerance test,TORCH testing and hysterosalpingography), were eligible to participate. Previous pregnancies were diagnosed by positive fetal cardiac pulsations by transvaginal ultrasound examination.

Patients with known causes of miscarriage as chromosomal abnormalities, uterine malformations, Antiphospholipid syndrome and endocrine abnormalities as thyroid disorders and diabetes mellitus were excluded from the study.

\subsection{Interventions}

Patients were scheduled for appointment for Gynecological examination immediately after the end of menstruation. All procedures were performed by the same physician.

On the scheduled day, the participants were prepared for a gynecological examination and the uterine cervix was identified using a Cusco's vaginal speculum.

Study group $(\mathbf{n = 6 2})$ : endometrial scratching was performed once with a pipelle de Cornier .The pipelle was introduced gently through the cervix up to the uterine fundus with regular back-and-forth movements over 1 minute to cover the entire endometrium.

Control group (n=64): Drying of the cervix with a gauze for 1 minute was performed (Sham procedure).

Induction of ovulation was scheduled in the day 2-3 of the next cycle using clomiphene citrate $50 \mathrm{mg}$ (Clomid, $50 \mathrm{mg}$ tablets, Sanofi-aventis, USA) in the classical protocol starting by $100 \mathrm{mg}$ per day for 5 days. Folliculometry was started on day 8 till confirmation of ovulation and administration of human chorionic gonadotrophins (Epifasi $5000 \mathrm{IU}$, ampoule, EIPICO pharmaceuticals, Egypt).

Pregnancy was diagnosed by positive pregnancy test in the serum to be confirmed by transvaginal ultrasound for the presence positive fetal cardiac pulsations. Further antenatal care visits were scheduled in the outpatient clinic every 2-4 weeks to record the obstetric outcome till delivery.

\subsection{Outcomes}

Clinical pregnancy rate, defined as the presence of at least one fetus with heart beat, live birth rate defined as at least one live-born baby, multiple pregnancy rate defined as the presence of more than one fetus with heart beat per clinical pregnancy; spontaneous miscarriage rate defined as loss of a clinical pregnancy before 20 completed weeks of gestation per clinical pregnancy and preterm delivery defined as delivery before completed 37 weeks per clinical pregnancy. Live birth rate was the primary outcome measure in this study.

\subsection{Sample Size}

The assumed total sample size of the study was actually calculated according to a proposed type I error of 5\% with an expected difference between rates of live-birth in study groups of $10 \%$. Type II error was proposed to be $20 \%(\beta=20 \%)$ hence the power was set at $(1-\beta, 80 \%)$. Accordingly, 60 women were needed in each group.

\subsection{Randomization and Blinding}

Enrolled patients were randomly assigned into two groups according to the method of intervention. Randomization in 1:1 ratio was carried out using computer-generated simple random tables.

All the study participants were blinded to intervention assignment for the duration of the study.

\subsection{Statistical Analysis}

Statistical analysis was performed using Statistical Package for the Social Sciences Version 16 (IBM Corp., Armonk, NY, USA). Quantitative data are expressed as means and standard deviations.

Chi-squared test and t-test were used to compare the two groups. $\mathrm{P}<0.05$ was considered to indicate significance and $p<0.001$ was considered to indicate strong significance. P- value in bold in the tables is statistically significant. 


\section{RESUlTS}

A total of 186 patients with repeated first trimester spontaneous miscarriage were assessed for eligibility, 56 patients were excluded (46 patients did not meet the inclusion criteria and 10 patients declined to participate).

130 patients were eligible and participate and equally allocated into two study groups (65 patients per group), 4 patients lost follow up in the study group and 1 patient in the control group (Figure 1).

Table (1) reveals the patients' characteristics and ovulation induction details. There was no significant difference between the two groups regarding age, parity, body mass index, number of abortions, day 3 FSH and LH, number of cycles of induction and the endometrial thickness in the cycle that resulted in pregnancy $(\mathrm{p}>0.05)$.

Table (2) shows the obstetric outcome. There was no significant difference between the two groups regarding clinical pregnancy rate, multiple pregnancy rate, preterm delivery, admission to NICU and neonatal death $(p>0.05)$. There was a significant difference between the two groups regarding the miscarriage rate which was higher in the control group $(\mathrm{p}<0.05)$ and live pregnancy rate which was higher in the study group $(\mathrm{p}<0.05)$.

Table1. Patients' characteristics and ovulation induction results

\begin{tabular}{|c|c|c|c|c|}
\hline & $\begin{array}{l}\text { Study group } \\
(\mathbf{n = 6 2})\end{array}$ & $\begin{array}{l}\text { Control group } \\
(n=64)\end{array}$ & $\begin{array}{l}\text { Student t- } \\
\text { test }\end{array}$ & P-value \\
\hline Age (years) & $29.7 \pm 1.5$ & $29.8 \pm 1.4$ & 0.38 & $>0.05$ \\
\hline $\begin{array}{l}\text { Parity: } \\
\text {-P0 } \\
\text {-P1 }\end{array}$ & $\begin{array}{l}51(82.3 \%) \\
11(17.7 \%)\end{array}$ & $\begin{array}{l}52(81.25 \%) \\
12(18.75 \%)\end{array}$ & $0.08^{*}$ & $>0.05$ \\
\hline Number of miscarriages & $5.4 \pm 1.3$ & $5.5 \pm 1.2$ & 0.45 & $>0.05$ \\
\hline Body mass index $\left(\mathrm{Kg} / \mathrm{m}^{2}\right)$ & $25.9 \pm 2.1$ & $26.4 \pm 1.8$ & 1.4 & $>0.05$ \\
\hline $\begin{array}{l}\text { Day } 3 \\
\text { FSH (IU/L) } \\
\text {-LH (IU/L) }\end{array}$ & $6.2 \pm 2.6 \quad 8.4 \pm 1.2$ & $6.3 \pm 2.5 \quad 8.3 \pm 1.3$ & $0.22 * 0.45$ & $\begin{array}{l}>0.05 \\
>0.05\end{array}$ \\
\hline $\begin{array}{l}\text { Number of ovulation induction } \\
\text { cycles } \\
\text { One } \\
\text {-Two } \\
\text {-Three }\end{array}$ & $\begin{array}{l}13(20.9 \%) \\
28(45.1 \%) \\
21(34 \%)\end{array}$ & $\begin{array}{l}15(23.4 \%) \\
29(45.3 \%) \\
20(31.3 \%)\end{array}$ & $0.12 *$ & $>0.05$ \\
\hline $\begin{array}{l}\text { Endometrial thickness }(\mathrm{mm}) \text { in } \\
\text { the cycle resulted in pregnancy }\end{array}$ & $7.8 \pm 1.3$ & $7.7 \pm 1.4$ & 0.42 & $>0.05$ \\
\hline
\end{tabular}

*Chi square test, FSH=Follicle stimulating hormone, LH=Leutinizing hormone.

Table2. The obstetric outcome

\begin{tabular}{|c|c|c|c|c|c|}
\hline & $\begin{array}{l}\text { Study group } \\
(\mathrm{n}=62)\end{array}$ & $\begin{array}{l}\text { Control } \\
\text { group }(n=64)\end{array}$ & $\begin{array}{l}\text { Chi-square } \\
\text { test }\end{array}$ & P-value & $\begin{array}{l}\text { Odd's ratio (at } \\
95 \% \mathrm{CI} \text { ) }\end{array}$ \\
\hline $\begin{array}{l}\text { Clinical pregnancy rate } \\
\text { per cycle } \\
\text { - One } \\
\text { - Two } \\
\text { - Three }\end{array}$ & $\begin{array}{l}13(20.9 \%) \\
28(45.1 \%) \\
21(34 \%)\end{array}$ & $\begin{array}{l}15(23.4 \%) \\
29(45.3 \%) \\
20(31.3 \%)\end{array}$ & $\begin{array}{l}0.120 .16 \\
0.13\end{array}$ & $\begin{array}{l}0.45 \\
0.43 \\
0.44 \\
\end{array}$ & $\begin{array}{l}0.89(0.39-2.08) \\
1(0.53-1.86) \\
1.08(0.54-2.19)\end{array}$ \\
\hline Multiple pregnancy rate & $8(12.9 \%)$ & $10(15.6 \%)$ & 0.18 & 0.42 & $0.83(0.31-2.23)$ \\
\hline Miscarriage rate & $24(38.7 \%)$ & $38(59.4 \%)$ & 2.15 & 0.015 & $0.65(0.35-1.21)$ \\
\hline $\begin{array}{l}\text { Preterm delivery } \\
-34 \text { to } 366 / 7 \text { days } \\
-28 \text { to } 336 / 7 \text { days } \\
-<28 \text { weeks }\end{array}$ & $\begin{array}{l}14(22.6 \%) \\
8 \\
4 \\
2\end{array}$ & $\begin{array}{l}15(23.4 \%) \\
7 \\
5 \\
3\end{array}$ & 0.11 & 0.45 & $0.96(0.43-2.16)$ \\
\hline Live birth rate & $36(58.1 \%)$ & $20(31.2 \%)$ & 2.86 & 0.002 & $1.86(0.97-3.55)$ \\
\hline Admission to NICU & $12(19.3 \%)$ & $13(20.3 \%)$ & 0.08 & 0.46 & $0.95(0.4-2.25)$ \\
\hline Neonatal death & $5(8.06 \%)$ & $7(10.9 \%)$ & 0.24 & 0.40 & $0.74(0.22-2.45)$ \\
\hline
\end{tabular}

NICU=Neonatal intensive care unit, 95\%CI=95\% Confidence interval. 


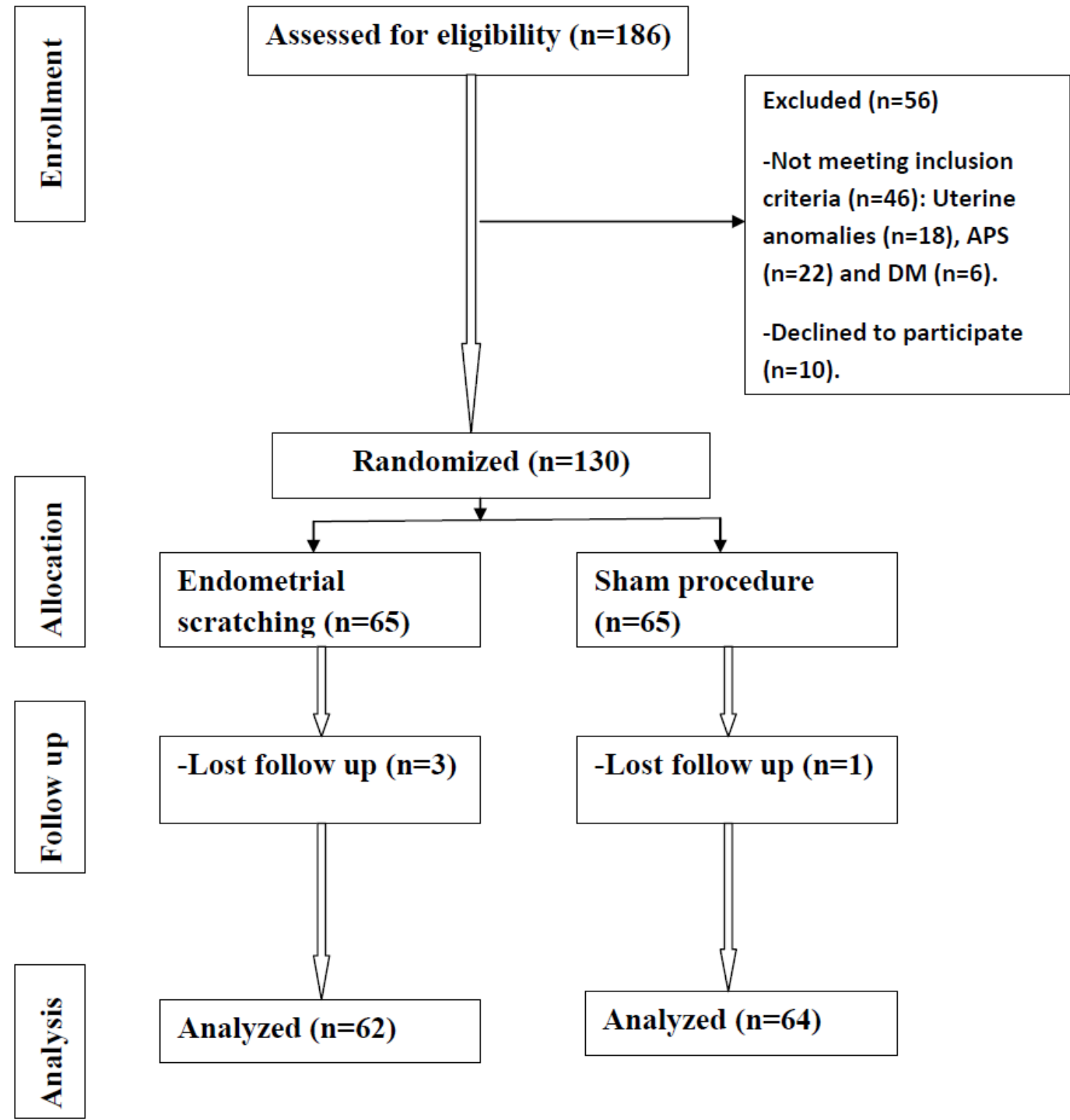

Figure1. Flow Diagram

\section{DISCUSSION}

We observed a significant benefit of endometrial scratching, performed once in patients with repeated first trimester miscarriage before starting induction of ovulation. The intervention was associated with increased live birth rate and decreased miscarriage rate without evidence of effect on clinical pregnancy rates, multiple pregnancy rates and preterm delivery rates.

We performed the procedure just once whilst in some other studies endometrial scratching was repeated $(7,8)$.

There were three possible mechanisms by which endometrial scratching may increase the receptivity and improve the clinical pregnancy rate of IVF-ET which may be also effective in other situations.

First, local injury to the endometrium might induce the decidualization of the endometrium and increase its implantation rate (9). Second, endometrial healing following injury is associated with a significant increase in the secretion of cytokines and interleukins, which are beneficial to embryo implantation $(10,11)$. Finally, the third hypothesis is that endometrial maturation is abnormally advanced when controlled ovarian stimulation (COS) is performed during ART cycles $(7,12)$.

Endometrial scratching was tried prior to intrauterine insemination (IUI) cycles. In this randomized clinical trial 144 women were included randomly assigned to undergo endometrial biopsy between days $6-8$ of the previous menstrual cycle before IUI $(n=72$, IUI cycles $=126)$ or receive no 
interventions ( $\mathrm{n}=72$, IUI cycles=105). Application of local endometrial injury in the cycle before the IUI cycles is not associated with increased pregnancy rate per patient and per cycle, decreased abortion, and increased endometrial thickness (13).

Also, endometrial scratching was tried in couples with unexplained subfertility. A randomized controlled trial was conducted on 105 couples with unexplained infertility were randomly allocated into two groups: group A comprised 54 women who underwent endometrial scratching and group B included 51 women who underwent a placebo procedure. The main outcome measured was cumulative clinical pregnancy rate after 6 months and miscarriage rate. Clinical pregnancy rate was significantly higher in the women experiencing endometrial biopsy than in the control group (14).

Small number of participants, non recording of adverse effects of endometrial scratching (pain, vaginal bleeding) and Doppler studies of uterine arteries were the main limitations of this study.

This is the first study to evaluate the effect of endometrial scratching performed in women with recurrent first trimester miscarriage. Further research is also needed to explore the mechanisms underlying the benefit of endometrial scratching on reproductive outcome.

\section{ACKNOWLEDGEMENTS}

The authors would like to acknowledge the contribution of the residents and nursing staff of the Gynecology ward and outpatient clinic of Menoufia university Hospital.

\section{REFERENCES}

[1] Nastri CO, Gibreel A, Raine-Fenning N, Maheshwari A, Ferriani RA, Bhattacharya S, Martins WP. Endometrial injury in women undergoing assisted reproductive techniques. Cochrane Database Syst Rev 2012; 7:CD009517.

[2] Barash A, Dekel N, Fieldust S, Segal I, Schechtman E, Granot I. Local injury to the endometrium doubles the incidence of successful pregnancies in patients undergoing in vitro fertilization. Fertil Steril 2003; 79:1317-1322.

[3] Karimzadeh MA, Ayazi Rozbahani M, Tabibnejad N. Endometrial local injury improves the pregnancy rate among recurrent implantation failure patients undergoing in vitro fertilisation/intra cytoplasmic sperm injection: a randomized clinical trial. Aust N Z J Obstet Gynaecol 2009; 49:677-680.

[4] Karimzadeh MA, Oskouian H, Ahmadi S, Oskouian L. Local injury to the endometrium on the day of oocyte retrieval has a negative impact on implantation in assisted reproductive cycles: a randomized controlled trial. Arch Gynecol Obstet 2010; 281:499-503.

[5] Guven S, Kart C, Unsal M, Yildirim O, Odaci E, Yulug E. Endometrial injury may increase the clinical pregnancy rate in normoresponders underwent long agonist protocol intracytoplasmic sperm injection cycles with single embryo transfer. Fertil Steril 2011; 96:S277, P-574.

[6] Nastri CO, Ferriani RA, Raine-Fenning N, Martins WP. Endometrial scratching performed in the non-transfer cycle and outcome of assisted reproduction: a randomized controlled trial. Ultrasound Obstet Gynecol 2013; 42:375-382.

[7] Kolb BA, Paulson RJ. The luteal phase of cycles utilizing controlled ovarian hyperstimulation and the possible impact of this hyperstimulation on embryo implantation. Am J Obstet Gynecol 1997; 176: 1262-1267.

[8] Narvekar SA, Gupta N, Shetty N, Kottur A, Srinivas M, Rao KA. Does local endometrial injury in the nontransfer cycle improve the IVF-ET outcome in the subsequent cycle in patients with previous unsuccessful IVF? A randomized controlled pilot study. J Hum Reprod Sci 2010; 3: $15-19$.

[9] Li R, Hao G. Local injury to the endometrium: its effect on implantation. Curr Opin Obstet Gynecol 2009; 21:236-239.

[10] Sherer DM, Abulafia O. Angiogenesis during implantation, and placental and early embryonic development. Placenta 2001; 22: 1-13. 
[11] Gnainsky Y, Granot I, Aldo PB, Barash A, Or Y, Schechtman E, Mor G, Dekel N. Local injury of the endometrium induces an inflammatory response that promotes successful implantation. Fertil Steril 2010; 94:2030-2036.

[12] Lass A, Peat D, Avery S, Brinsden P. Histological evaluation of endometrium on the day of oocyte retrieval after gonadotrophin-releasing hormone agonist-follicle stimulating hormone ovulation induction for in-vitro fertilization. Hum Reprod 1998; 13:3203-3205.

[13] Zarei A, Alborzi S, Dadras N, Azadi G. The effects of endometrial injury on intrauterine insemination outcome: A randomized clinical trial. Iran J Reprod Med. 2014 Sep; 12(9):649-52.

[14] Gibreel A, Badawy A, El-Refai W, El-Adawi N. Endometrial scratching to improve pregnancy rate in couples with unexplained subfertility: a randomized controlled trial. J Obstet Gynaecol Res. 2013 Mar; 39(3):680-4. 